\title{
Awareness and Perception Analysis of Small Medium Enterprise and Start-up Towards FinTech Instruments: Crowdfunding and Peer-to-Peer Lending in Malaysia
}

\author{
Nasrul Hakim Ghazali*, Takashi Yasuoka \\ Graduate School of Engineering Management, Shibaura Institute of Technology, Tokyo, Japan \\ Email address: \\ ir.n.hakim@gmail.com (N. H. Ghazali) \\ *Corresponding author \\ To cite this article: \\ Nasrul Hakim Ghazali, Takashi Yasuoka. Awareness and Perception Analysis of Small Medium Enterprise and Start-up Towards FinTech \\ Instruments - Crowdfunding and Peer-to-Peer Lending in Malaysia. International Journal of Finance and Banking Research. \\ Vol. 4, No. 1, 2018, pp. 13-24. doi: 10.11648/j.ijfbr.20180401.12
}

Received: January 31, 2018; Accepted: February 16, 2018; Published: March 19, 2018

\begin{abstract}
This study aims to analyze the awareness and perception of Malaysian Small Medium Enterprises and start-ups on the existence of alternatives financing channels such as Peer-to-Peer lending and crowdfunding in supporting the growth and expansion of their business in the future. Results indicate that, at present, the level of awareness of most respondents is still insufficient on Peer-to-Peer lending and crowdfunding as alternative financing instruments. However, based on the perception results, a majority of them have a slightly positive response or perception to the development of FinTech. These results suggest that there is a need and opportunity to raise awareness among Small Medium Enterprises and start-ups by authorized government related body.
\end{abstract}

Keywords: Awareness, Perception, FinTech, Alternative Financing Instrument, SME, Malaysia

\section{Introduction}

Small and medium-sized enterprises (SMEs) and start-ups play a significant role as the primary driver for economic growth and a force in job creation. However, these SMEs and start-ups have difficulty in securing proper financing to prosper. The global financial crisis, which was occurred in 2007-2008, coupled with stricter regulation for loans to SMEs and start-ups, has made it even more difficult for SMEs and start-ups to secure financing. Reasons for this issue are varied: the finances of SMEs and start-ups are characterized by high risk, yet are low scale. As for traditional lenders such as banks, due to small-sized of a loan, lending credit to small businesses is often too costly and give a little return. Driven further by regulation, banks have reduced their exposure to smaller companies in recent years. In addition to this, small businesses also often lack the knowledge, skills, capabilities, and resources to manage finance in a sophisticated manner and to conduct systematic fundraising. However, the global financial crisis and the obstacle to getting a loan from banks have also created disruptors in the FinTech (the use of technology and innovative business models in financial services) area who, with their creative ways have provided alternative ways for SMEs to secure funding for their growth. Examples of alternative financing instruments are shown in Table 1.

Of the alternatives financing instruments, the two most common alternative financing channels are peer-to- peer (P2P) lending and crowdfunding. P2P lending or social lending is the practice of matching borrowers and lenders via online platforms. Borrowers are generally able to obtain funds quickly and typically at the same or lower interest rates than traditional financial intermediaries. Meanwhile, the crowdfunding model is the practice of raising small amounts of money for a project from a large, potentially geographically distributed a pool of people or the "crowd." This practice is typically achieved using the internet as an online platform. Crowdfunding exists in different forms based on the benefits afforded to funders. The most common types of crowdfunding are donation and equity crowdfunding. The donation crowdfunding is often used when there is a need to raise money to help people in need- wherein the 
funder receives no explicit compensation for their financial support. The Equity Crowdfunding model is more straightforward and similar to traditional investment models. Funders who provide financial support obtain a beneficial interest in the form of a shareholding or equity in the company, in return for their investment. Alternative finance channels such as P2P and crowdfunding are potential to generate undeniable funding support and growth opportunities for SMEs and start-ups. However, they also face challenges in both demand and supply side due to limited awareness of their existence and an uncertain FinTech regulatory framework in many countries.

Table 1. Alternative Financing Instruments.

\begin{tabular}{llll}
\hline Low risk/return & Low risk/return & Medium risk/ return & High risk/return \\
\hline Asset-based finance & Alternative debt & "Hybrid" instruments & Equity instruments \\
\hline & & 1. Subordinated loans/bonds & \\
1. Asset-based lending & 1. Corporate bonds & 2. Silent participations & 1. Private equity \\
2. Factoring & 2. Securitized debt & 3. Participating loans & 2. Venture capital \\
3. Purchase order finance & 3. Covered bonds & 4. Profit participation rights & 3. Business angels \\
4. Warehouse receipts & 4. Private placements & 5. Convertible bonds & 4. Specialized platforms for public listing of SMEs \\
5. Leasing & 5. Crowdfunding & 6. Bonds with warrants & 5. Crowdfunding (equity) \\
\hline
\end{tabular}

Source: Lucia, C. (2015).

\section{Financial Market Development in Malaysia}

\subsection{Access to Financing}

In the recent, The Global Economic Competitiveness Report 2017-2018 published by The World Economic Forum (WEF) on 26 September 2017, Malaysia has successfully moved up one place to the $23^{\text {rd }}$ position from the $24^{\text {th }}$ spot in the 2016-2017 report. The report indicated that economy of Malaysia and its financial market development had grown steadily ever since the oil price crisis in 2011 and one of the most competitive emerging economies in the Asia region.
However, also shown in the report was that one of the significant challenges for Malaysia to increase business activity in the country is the access to financing as illustrated in Figure 1 below.

Realizing the fact that these new innovative finance of FinTech can benefit SMEs and start-ups in Malaysia, as well as the disruptive risk it brings to the traditional financial institution, the Malaysian Government through its Central Bank of Malaysia has taken a positive approach to managing and adapting to the emerging risk emanating from these new solutions. P2P lending and Crowdfunding which are part of Fintech have been officially recognized by the Malaysian

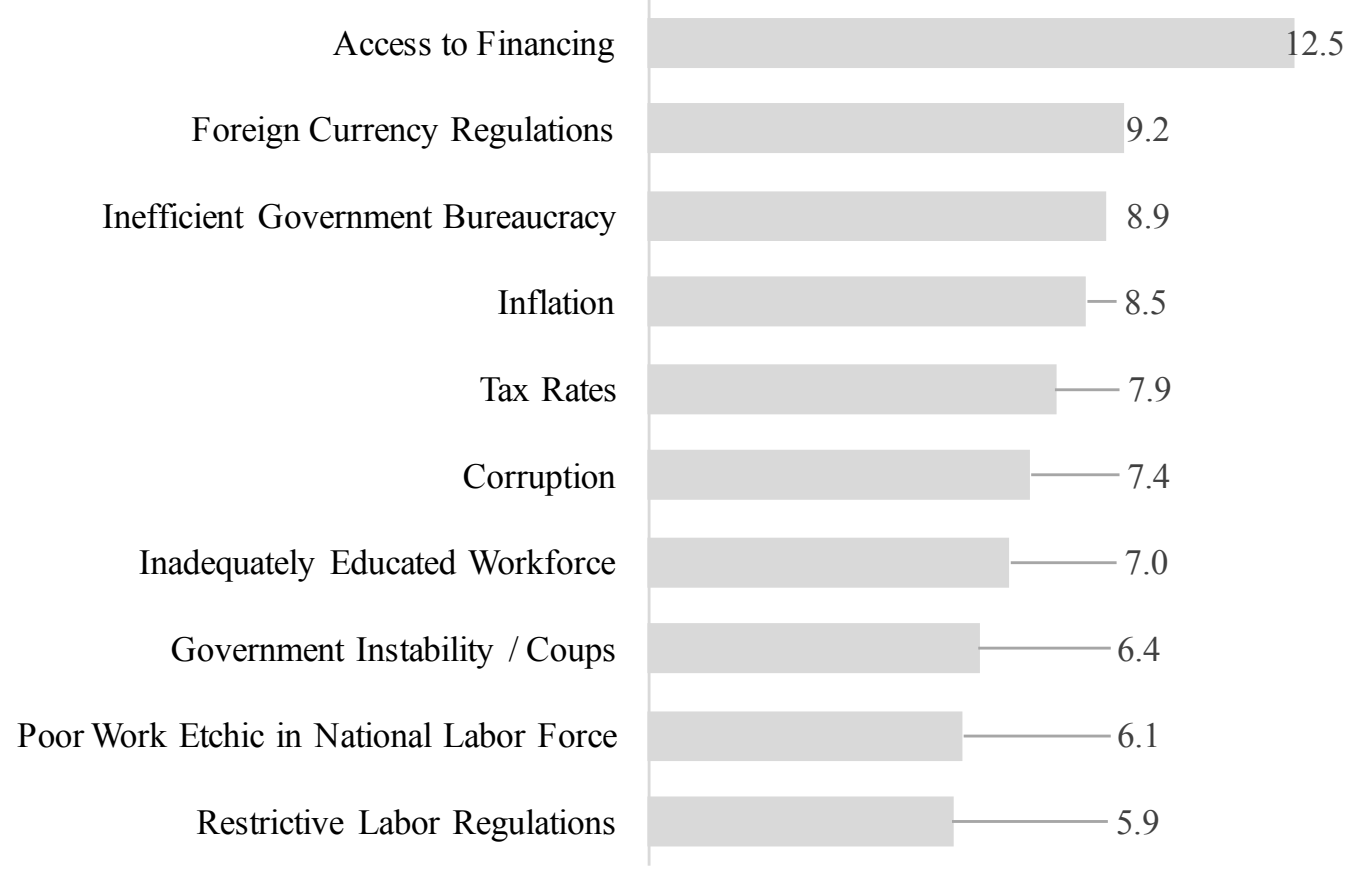

Source: The Global Economic Competitiveness Report 2016-2017, World Economic Forum (2018)

Figure 1. Most problematic factors for doing business in Malaysia. 


\section{SMEs are the backbone of the economy}

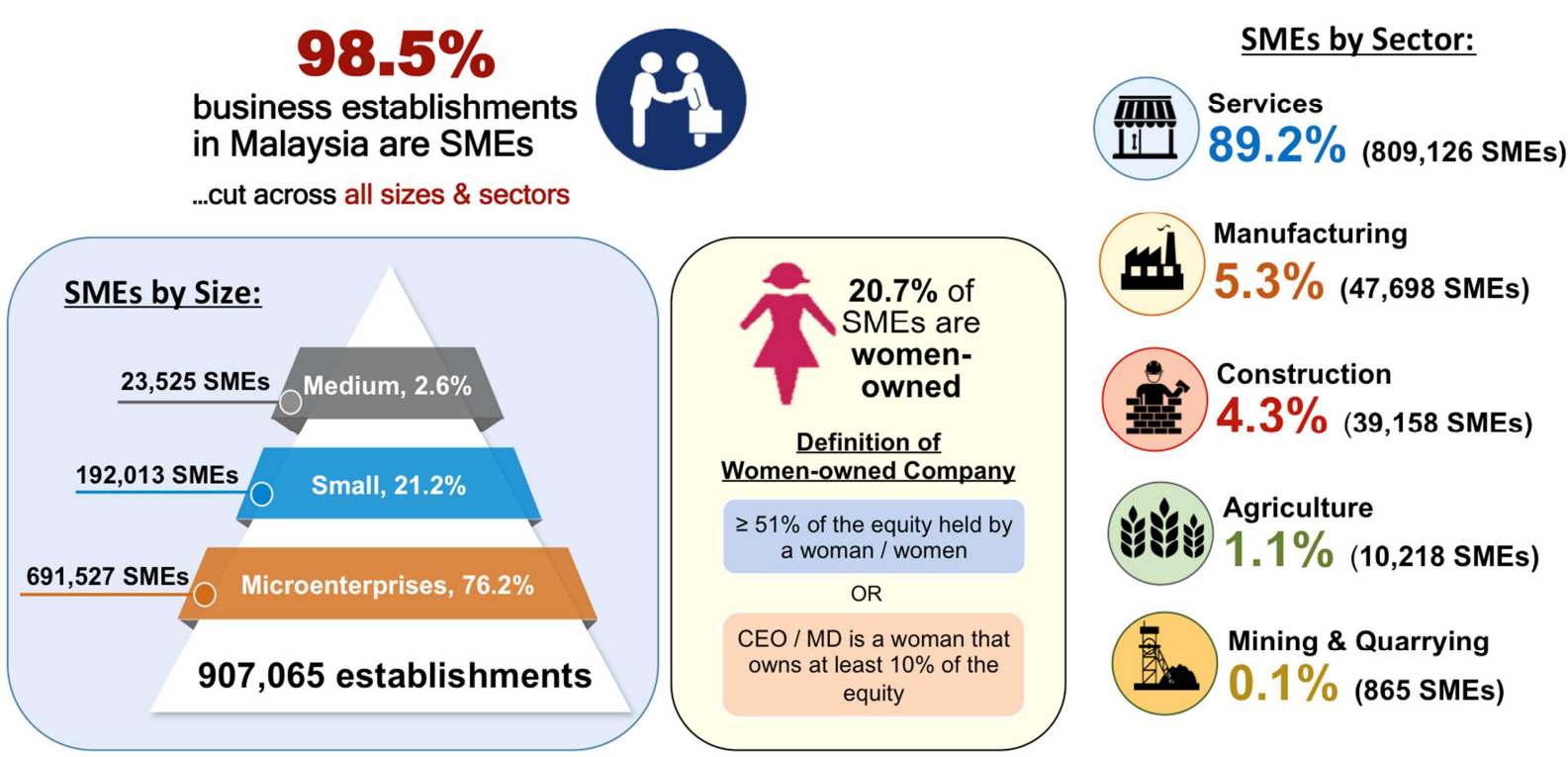

Figure 2. Overview of Malaysian SMEs (Source: Department of Statistics Malaysia).
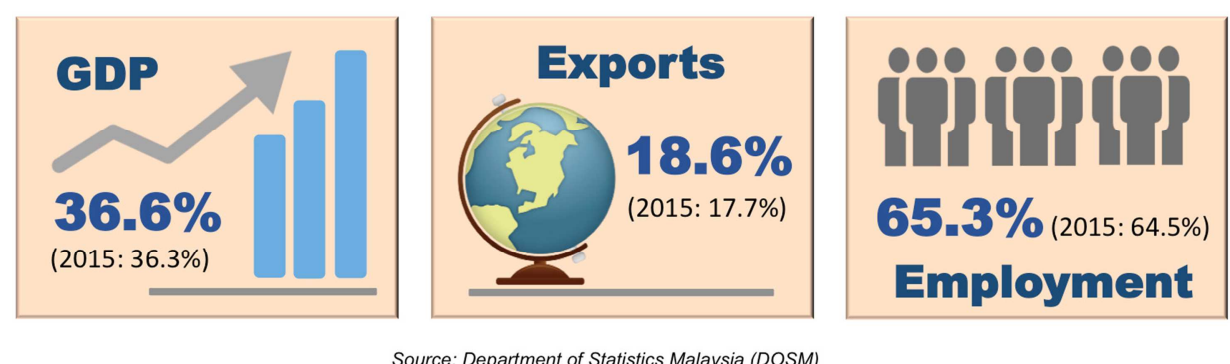

Figure 3. Contribution of Malaysian SMEs to Malaysia Economy (Source: Department of Statistics Malaysia).

Government since October 2016 through the introduction of Fintech Regulatory Sandbox Framework. This step makes Malaysia become the first Asia Pacific nation to regulate for equity crowdfunding in its drive to develop the FinTech agenda. Later in November 2016, Securities Commission of Malaysia (SC) announced six P2P Financing Operators in Malaysia to widen financing options for small and medium enterprises (SMEs).

Apart from Malaysia, other countries such as United Kingdom (UK), Hong Kong and Singapore are also adopting regulatory sandbox to provide flexible regulations for the FinTech companies to test their innovative product and services. However, the regulatory sandbox in Malaysia is a little bit different from the others. For example, in Malaysia, only authorized firms with a track records can participate in the sandbox while in the UK, both authorized and unauthorized firms may apply for the participation.

\subsection{Challenges in Alternative Financial Market}

As mentioned in the above paragraph, this new forms of innovative finance such as $\mathrm{P} 2 \mathrm{P}$ lending and crowdfunding are supposed to increase the financing options available to the
SMEs and start-ups. However, there are challenges from demand-side such as the lack of financial knowledge or awareness of many entrepreneurs and business owners on this alternative financing instruments. Most of them are unaware of the existence of alternatives to bank lending and, even if they are, are often unable or unwilling to comply with the requirements of professional investors. Consequently, prevents SMEs and start-ups from seeking out the instruments that are most suited to their needs.

\section{Research Objective}

Given the importance of the SMEs to the growth of the economy of Malaysia and the recent development of FinTech market in Malaysia, this study aims to measure the awareness and perception of Malaysian SMEs and start-ups on the existence of P2P lending and crowdfunding as a funding support for their business. In addition to that, this study also aims to find out what kind of factor or element that would increase the interest of SMEs and start-ups in utilizing instruments available in FinTech as one of the solutions for their financial need. 


\section{Research Methodology}

\subsection{Literature Review}

Study on awareness of FinTech has been carried out in many countries such as United Kingdom (UK), Latvia, Finland and many more. Saksonova and Kuzmina-Merlino (2017) reported that consumers were unaware of FinTech services in Latvia and their associated innovations and new financial product. In the UK, Baeck et al.(2014) reported that the level of awareness, as well as the nuances of perception about alternative finance among consumers and SMEs in the UK, was very low. As for the countries in Asia, no specific journal was found on the survey of awareness particularly between SMEs and FinTech in each country. However, there was a report from Ernst and Young (2017) as shown in Table 2 regarding FinTech Adoption Index in for Asia countries such as China, Japan, India, Singapore and Hong Kong, but still, no data was highlighted for Malaysia. As there is a limited reference to the awareness survey on FinTech in Asia, Saksanova (2017) and Baeck et al. (2014) were used as the main reference in this study. For the construction of questionnaire, a survey by the World Bank (2014) on the provision of financial services, in particular, financial services provided to small and medium enterprises (SMEs) is taken as a reference. Apart from that, the concept of AIDA Model regarding attention (awareness), interest and desire (perception) of SMEs and start-ups towards FinTech service is also utilized during the construction of the survey.

Table 2. Fintech Adoption Rate.

\begin{tabular}{ll}
\hline Country & Adoption Rate (\%) \\
\hline China & 69 \\
India & 52 \\
United Kingdom & 42 \\
Australia & 37 \\
United States & 33 \\
Singapore & 23 \\
Japan & 14 \\
\hline
\end{tabular}

Source: Ernst and Young (2017).

\subsection{Learning from China}

A case study on FinTech development in China is also taken as a reference in this study. Before 2000, the Chinese financial industry was lagging behind those of many other countries, and the financial infrastructure was insufficient, and commerce-related fraud was commonplace (Yongowoon \& Dong-Hee, 2015). However, since the establishment of Alibaba in 1999, now is the largest e-commerce company in China, the contribution of FinTech to the growth of SMEs and economy of China has started to be noticed.

In 2014, following the government's approval, a total of 250 companies in China received a payment license, including 90 for online payment and 37 for mobile phone payment with Alibaba as the frontrunner. As for July 2015, China's peer-to-peer (P2P) lending platforms counted 2,136, with settlements of about RMB82.5 billion transactions in that single month, making it the country with the most P2P platforms in the world. It is further reported the platform has delivered directly to the public and SMEs more than RMB251 billions of credit in 2014 (Douglas and Janos, 2015).

As cited by Asaba et al. (2016), based on China case study, there are three conditions observed to be important as essential success factors for the FinTech industry to support the growth of the SMEs: the digital technology adoption level of the SMEs, the financial literacy skills, and the regulatory frameworks. A simple comparison study as shown in Table 3 on above factors was also done between China and Malaysia to see the readiness of FinTech industry in Malaysia in supporting SMEs and start-ups.

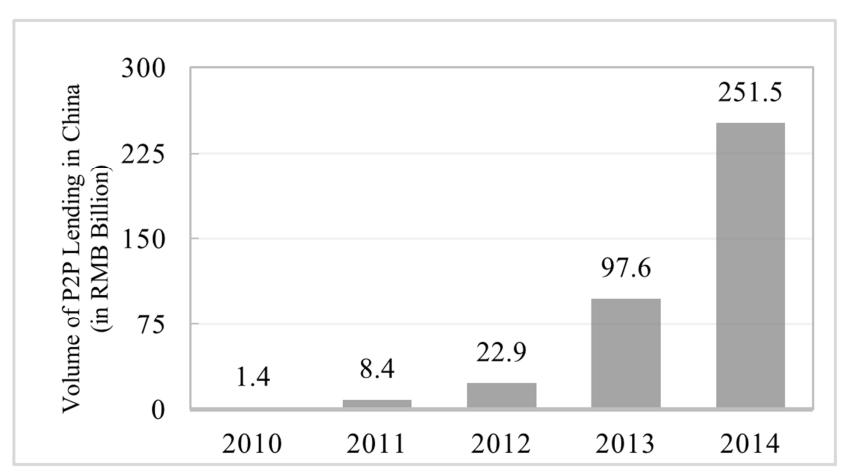

Source: Arner, D. W., \& Janos B. (2015)

Figure 4. Volume of P2P Lending in China.

Table 3. Comparison Study Between Malaysia and China in FinTech Development.

\begin{tabular}{lll}
\hline Key Indicator & China & Malaysia \\
\hline The digital technology adoption level & a) $89 \%$ using a mobile phone* & a) $76 \%$ using mobile phone** \\
of the SMEs & b) $45 \%$ internet users* & b) $32 \%$ internet users** \\
The financial literacy skills & $66^{* * *}$ & $67 * * *$ \\
& Less intervention in the early stage. $*$ & Financial Technology Regulatory Sandbox \\
The regulatory frameworks & Start to impose heavier regulation as the industry mature. * & Framework (Framework) is introduced**** \\
& Regulation, mostly promote risk management. * &
\end{tabular}

* Asaba et al. (2016)

** E-Readiness of Malaysian SMEs (2017)

***Asia/ Pacific - Youth: MasterCard Index of Financial Literacy 2013

**** Central Bank of Malaysia 


\subsection{Survey Construction and AIDA Model}

A total of 28 questions have been constructed for this survey. The questions in the survey were divided into 3 part, Part A: general questions, Part B: awareness-based questions and Part C: perception based questions. The contents of the survey are presented in Table 4. The objective of awareness-based the question is to find out whether the development of FinTech has caught the attention of SMEs and start-ups in Malaysia. As for the perception-based question, it was designed to find out the interest and desire of SMEs and start-ups from the development of FinTech in Malaysia. These questions were design based on AIDA Model Framework (Attention, Interest, Desire, and Action) as shown in Figure 5 below.

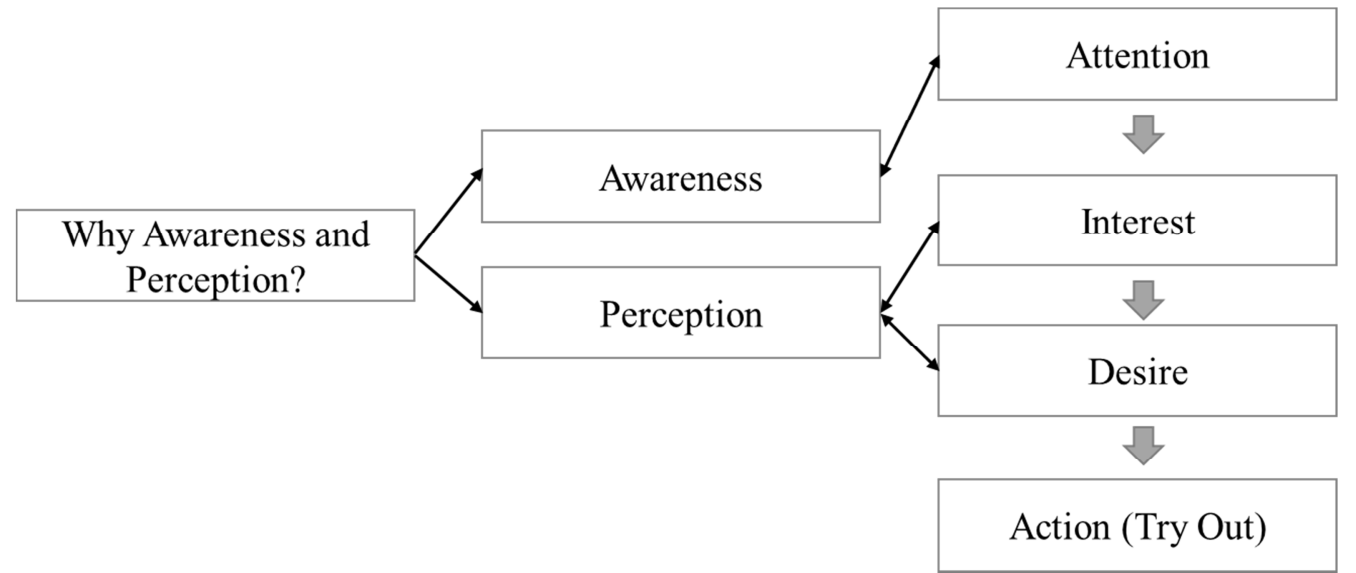

Figure 5. AIDA Model Framework based Survey.

Table 4. Contents of the Questionnaire (Q7-Q15 are 5 points Likert-scale questions).

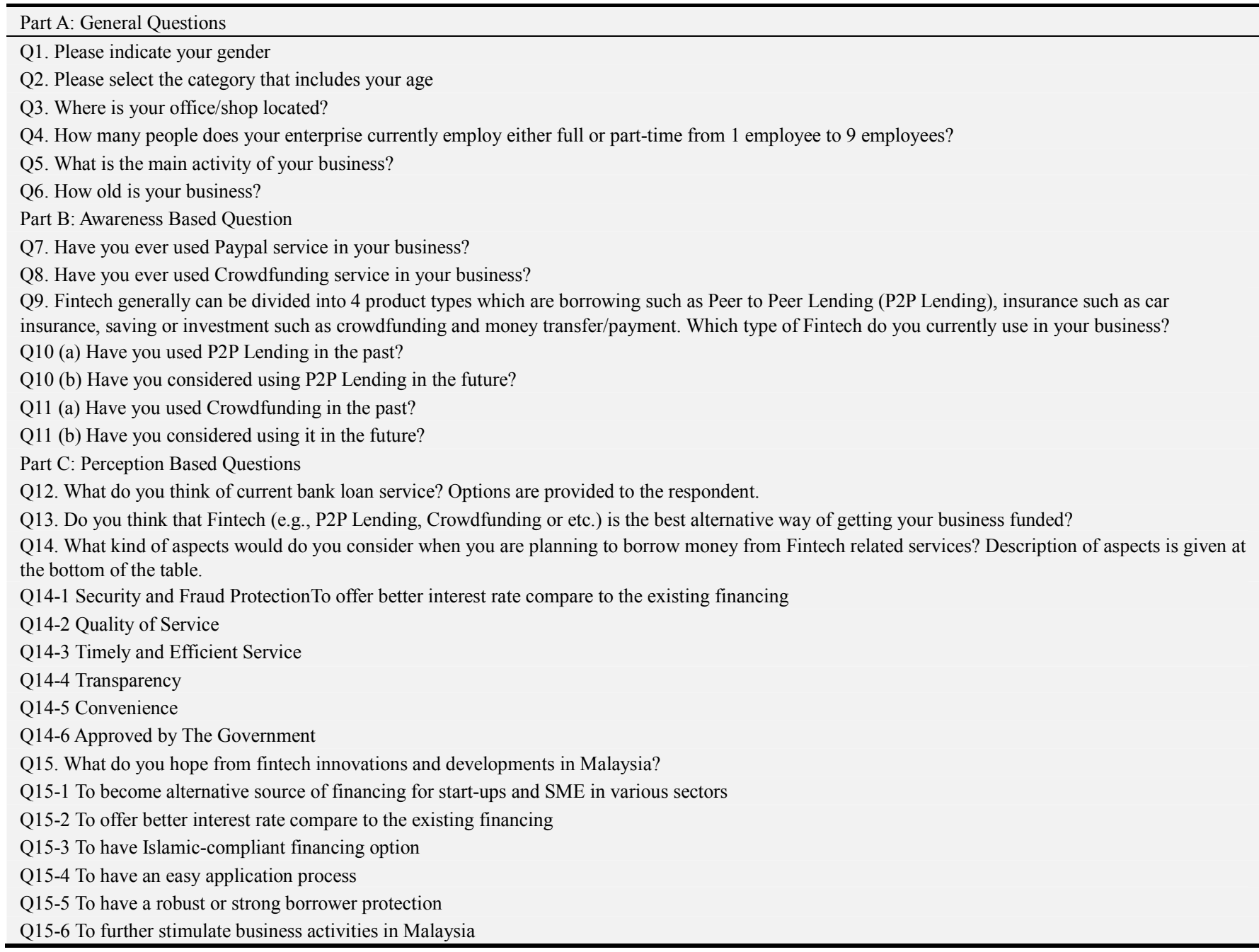




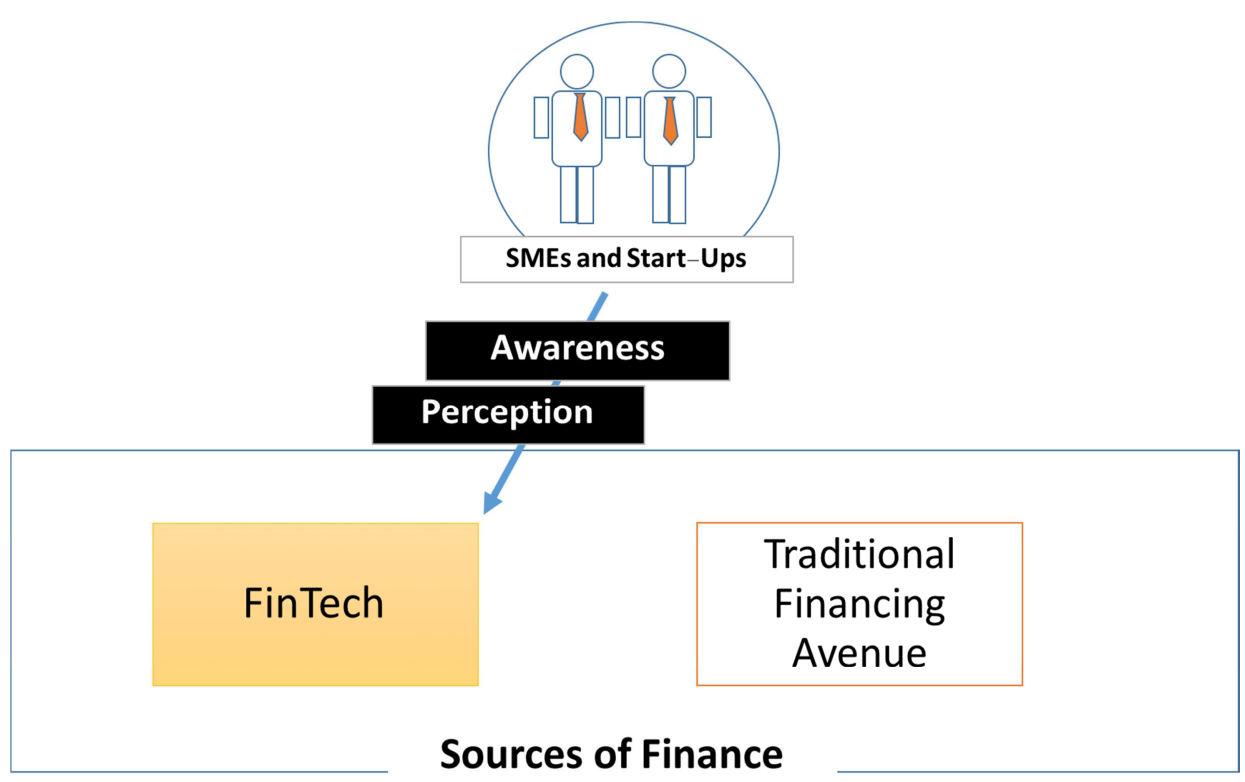

Figure 6. Illustration of Survey Methodology.

Table 5. Summary of Survey.

\begin{tabular}{ll}
\hline Duration & Aug. - Sept 2017 \\
\hline Respondent & Manager or Director of SMEs or Start-Up \\
Area & Kuala Lumpur and Selangor \\
\hline
\end{tabular}

\subsection{Explanation of Survey}

Figure 6 illustrates how this study was carried out. A set of close-ended questionnaires were distributed to the managers or directors of SME and start-up in Malaysia, specifically in the area of Kuala Lumpur and Selangor to get their feedback on Fintech and indirectly measure their awareness on Fintech development in Malaysia. The summary of the survey is shown in Table 5.

\section{Results and Discussion}

\subsection{Part A: The Respondents' Profile}

30 respondents representing different companies have been successfully obtained. The distribution of the respondents is nearly close as compared to the distribution of Malaysian SMEs in the National level as shown Figure 7, 9 and 10. The descriptive statistical analysis was conducted using the Statistical Package for Social Sciences (SPSS) software. Frequency distribution and measures of a central tendency by the mean and measures of variations by sample were utilized for data analysis.

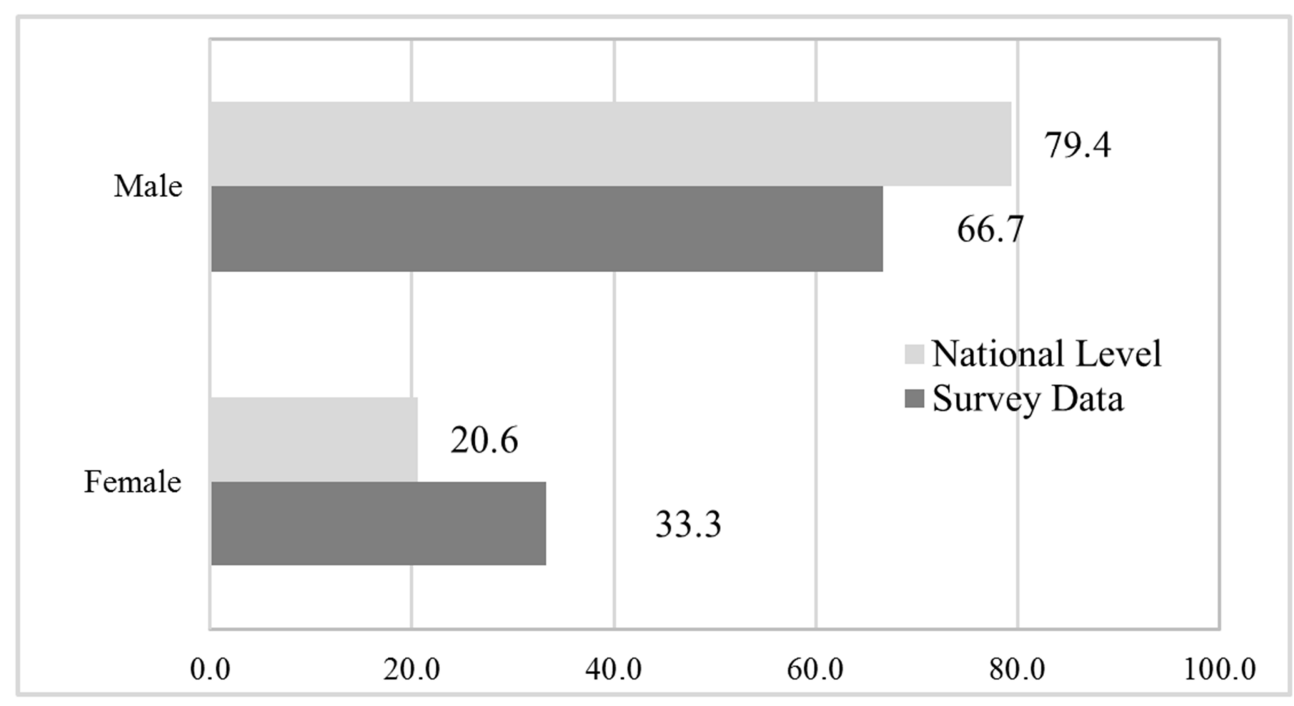

Figure 7. Respondents Profile (Gender). 


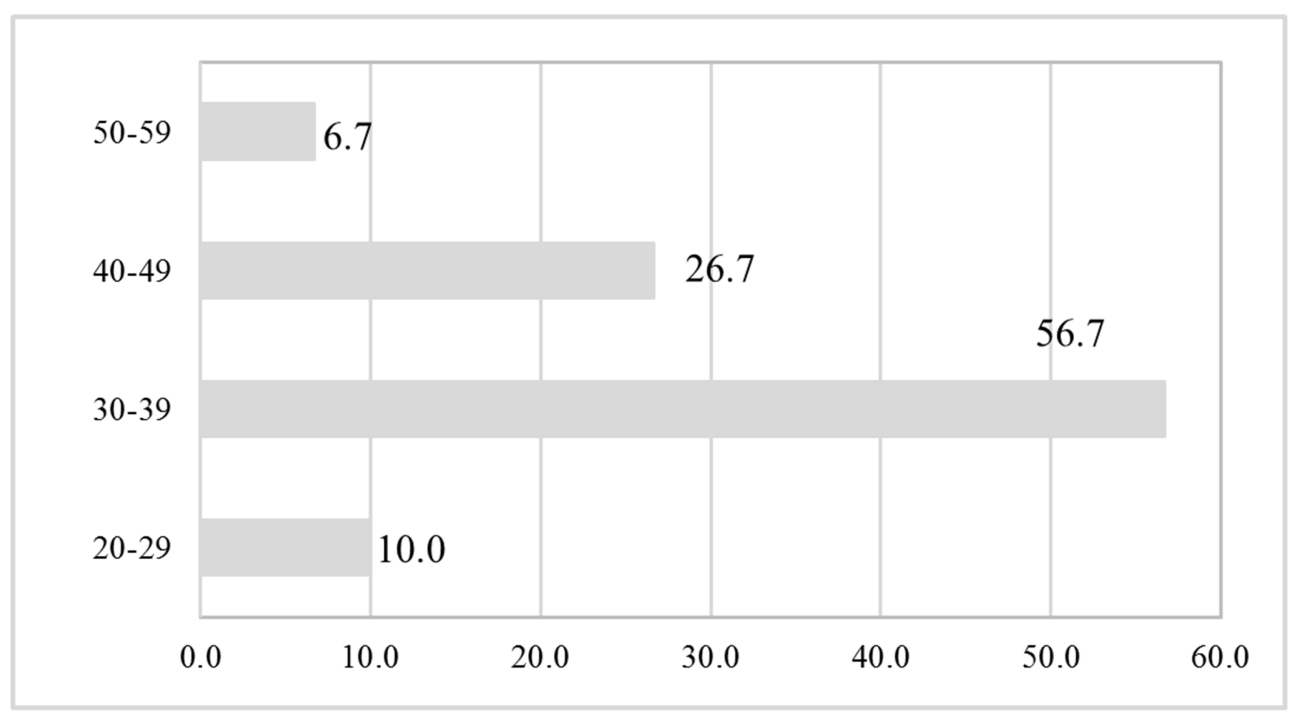

Figure 8. Respondents Profile (Group of Age). No details or breakdown data on age available from the Department of Statistics of Malaysia.

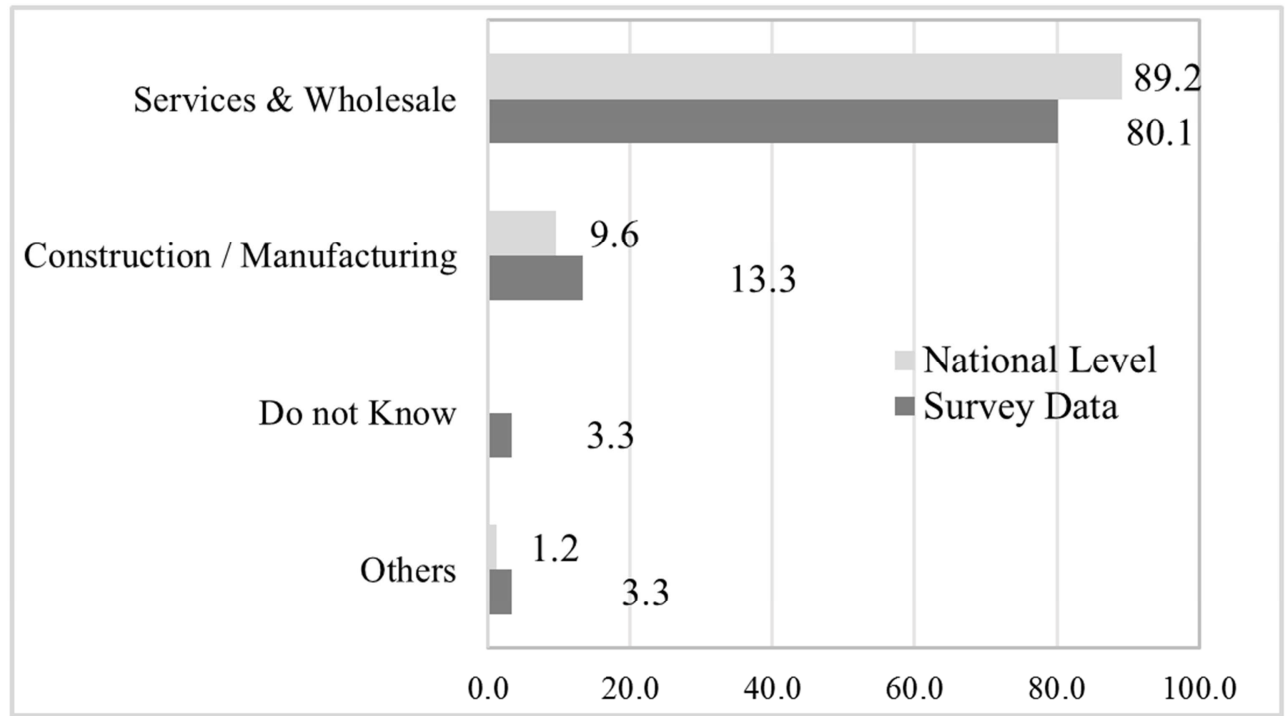

Figure 9. Respondents Activity of Business.

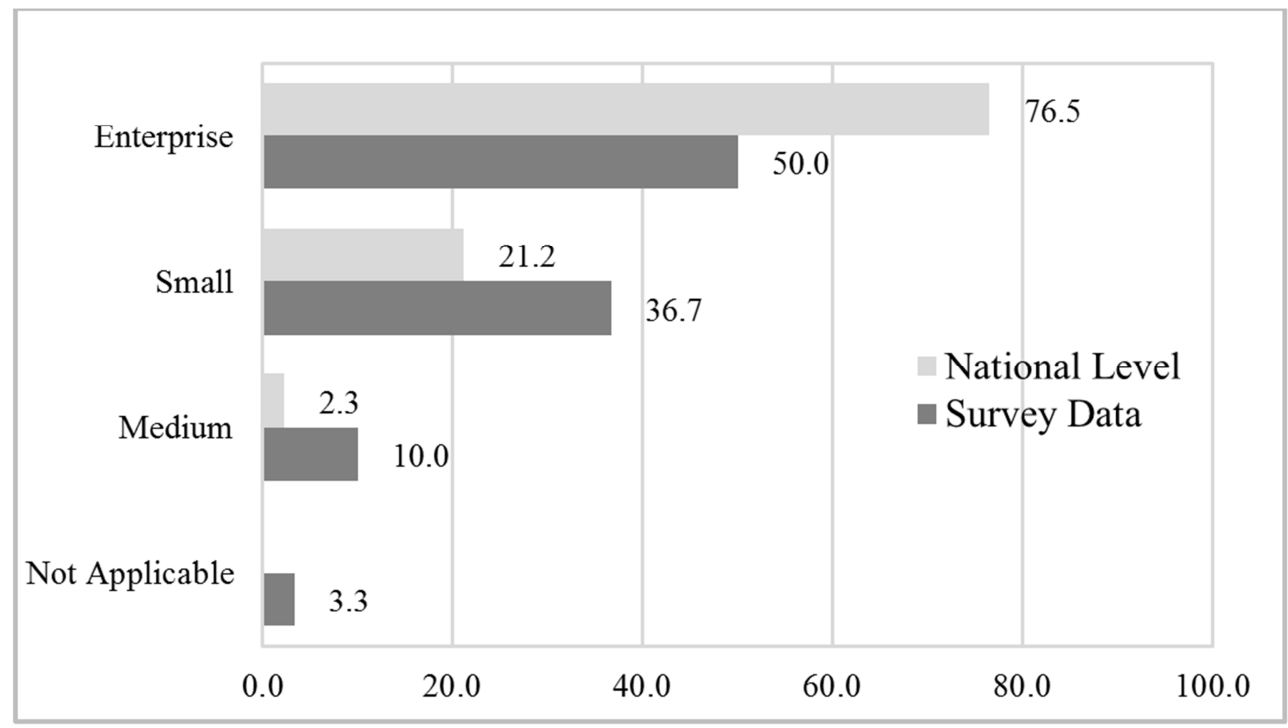

Figure 10. Respondents Size of Business. 


\subsection{Part B: Awareness Based Questions}

\subsubsection{SMEs and Start-ups Experience in FinTech}

In Q7 and Q8 of the second section of the questionnaire, the respondents were asked about experience in using technological innovation in FinTech such as PayPal and Crowdfunding. The results indicate that a majority of respondents did not have experience in using PayPal and crowdfunding as summarized in a mean $(\mu) \pm$ standard deviation $(\sigma)$ chart (Figure 11).

\subsubsection{FinTech Familiarity Among SMEs and Start-ups}

From the Q9, we found that $73.3 \%$ or 22 respondents were familiar and aware of the recent technological development in financial system such as online money transfer/payment $(60 \%)$, saving or online banking $(6.7 \%)$, investment and car insurance (3.3\% respectively). While $26.7 \%$ or 8 respondents answered, "none of the above." The results from Q7-Q9 show that most of the respondents have limited knowledge and awareness of the FinTech services provided by the non-bank financial institution.

\subsubsection{Consideration on Fin Tech in the Future}

Also in the second section of the questionnaire, respondents were explicitly asked their experience in using P2P lending and crowdfunding and whether they would consider using these new instruments in the future. A scale from one to five was used in this question where one, "I do not want to consider" and five, "I do want to consider". As shown in above Table 3, descriptive analysis through SPSS software indicated that a majority of respondents did not have an experience on both P2P lending (a mean of 1.17) and crowdfunding (a mean of 1.27). However, as for the consideration question on utilizing P2P lending and crowdfunding in the future, the result shows that most respondents are neutral to use P2P lending (a mean of 3.27) and crowdfunding (a mean of 3.13). Results are as shown in Figure $12(\mu \pm \sigma$ chart). 5.3. Part C: Perception Based Questions

\subsubsection{Perception on Current Financing Services Provided by Banks}

In the third section of the questionnaire, respondents were asked their opinion and perception of the current services provided by traditional financing specifically the bank lending. Issues listed in the Table 6 were identified from various sources such as newspaper articles and journals pertaining issues on loan services rendered by the bank to the SMEs and start-ups. Based on the multiple response data analysis through SPSS, interest rates or price too high, too much paperwork is involved and insufficient collateral or guarantee when borrowing are the top three issues identified. The general perception of respondents concerning FinTech (P2P lending, crowdfunding, and other instruments) as the best alternative way of getting their business funded was ranked on a scale from 1, "Strongly Disagree" to 5, "Strongly Agree." As shown in Figure 13 ( $\mu \pm \sigma$ chart), a mean of 3.63 is obtained showing that most people agree that FinTech is the best alternative way to getting their business funded.

Table 6. Perception of Current Bank Loan Services.

\begin{tabular}{ll}
\hline Perception on Current Bank Loan & Percent (\%) \\
\hline 1. Interest rates or price too high & 39.7 \\
2. Too much paperwork is involved & 31.7 \\
3. Insufficient collateral or guarantee & 12.7 \\
4. My application was rejected by bank & 4.8 \\
5. I do not need this type of financing & 3.2 \\
6. No bank loans are available & 3.2 \\
7. Reduced control over the enterprise & 3.2 \\
8. Everything is good & 1.6 \\
\hline
\end{tabular}

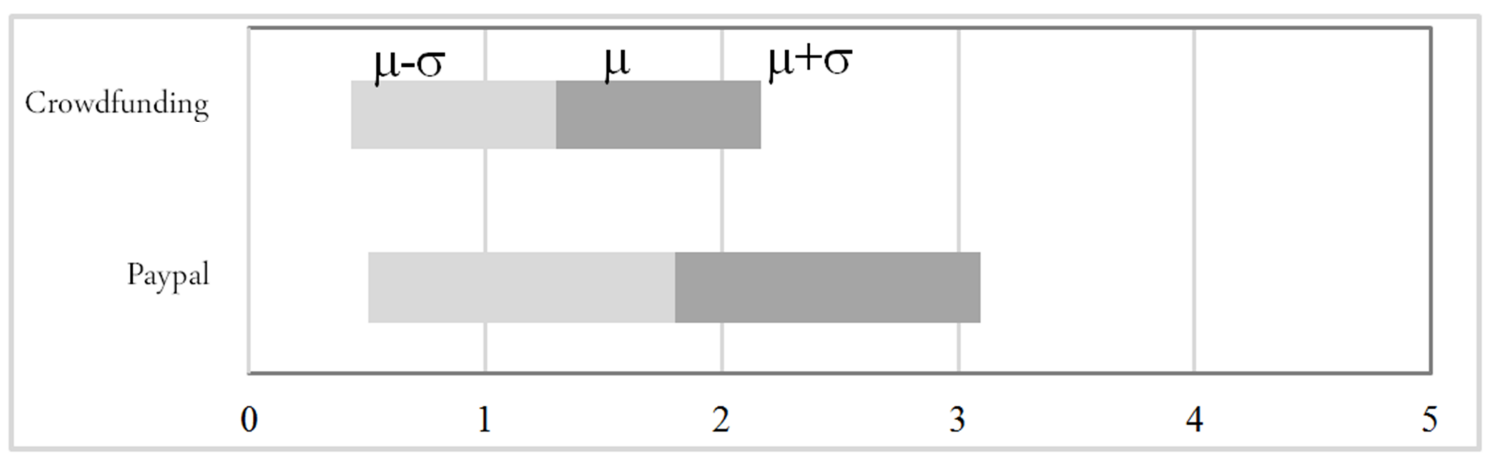

Figure 11. Respondents Experience on Crowdfunding and PayPal. 


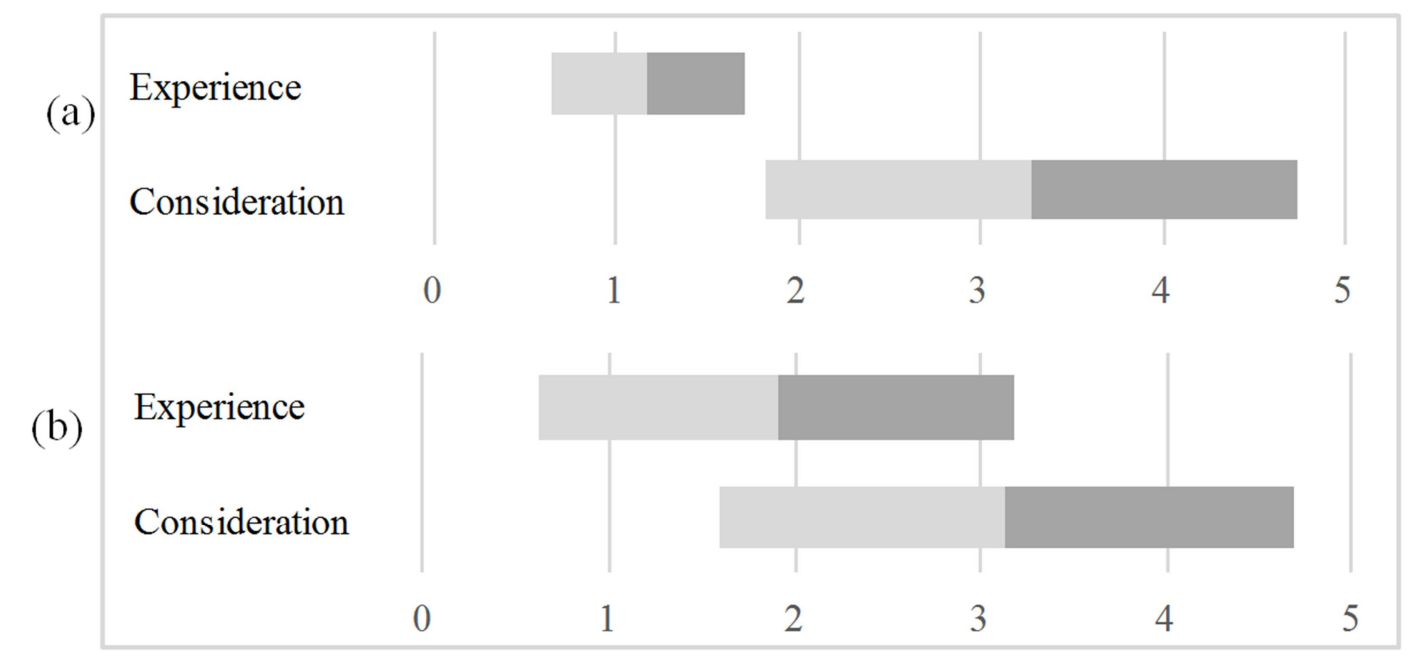

Figure 12. Respondents Experience and Consideration for (a) P2P Lending and (b) Crowdfunding.

\subsubsection{Perception of SMEs and Start-Ups on Fintech as Alternative Financing}

As shown in Figure $14(\mu \pm \sigma$ chart), respondents were asked what kind of element that they would consider when choosing P2P lending or crowdfunding as their source of financing. In this question, six elements were prepared based on the quality of current financial services and were ranked on a scale from 1, "Strongly Will Not Consider" to 5, "Strongly Will Consider." The result shows that element 'Approved by the Government' is the most considered element with a mean of 4.03 , followed by Transparency (a mean of 3.87), Convenience (a mean of 3.83) and Security and Fraud Protection (a mean of 3.80).

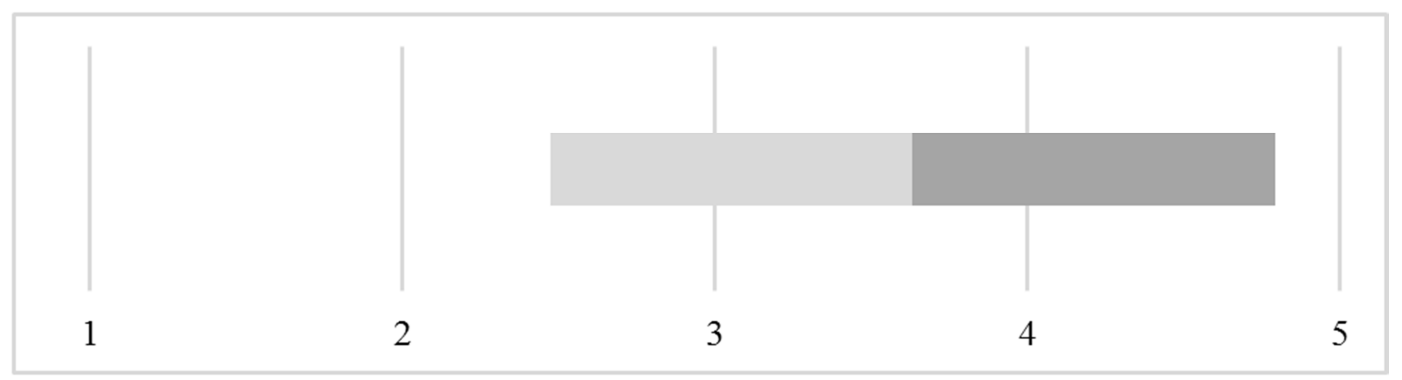

Figure 13. Perception on Fintech as The Best Alternative Financing.

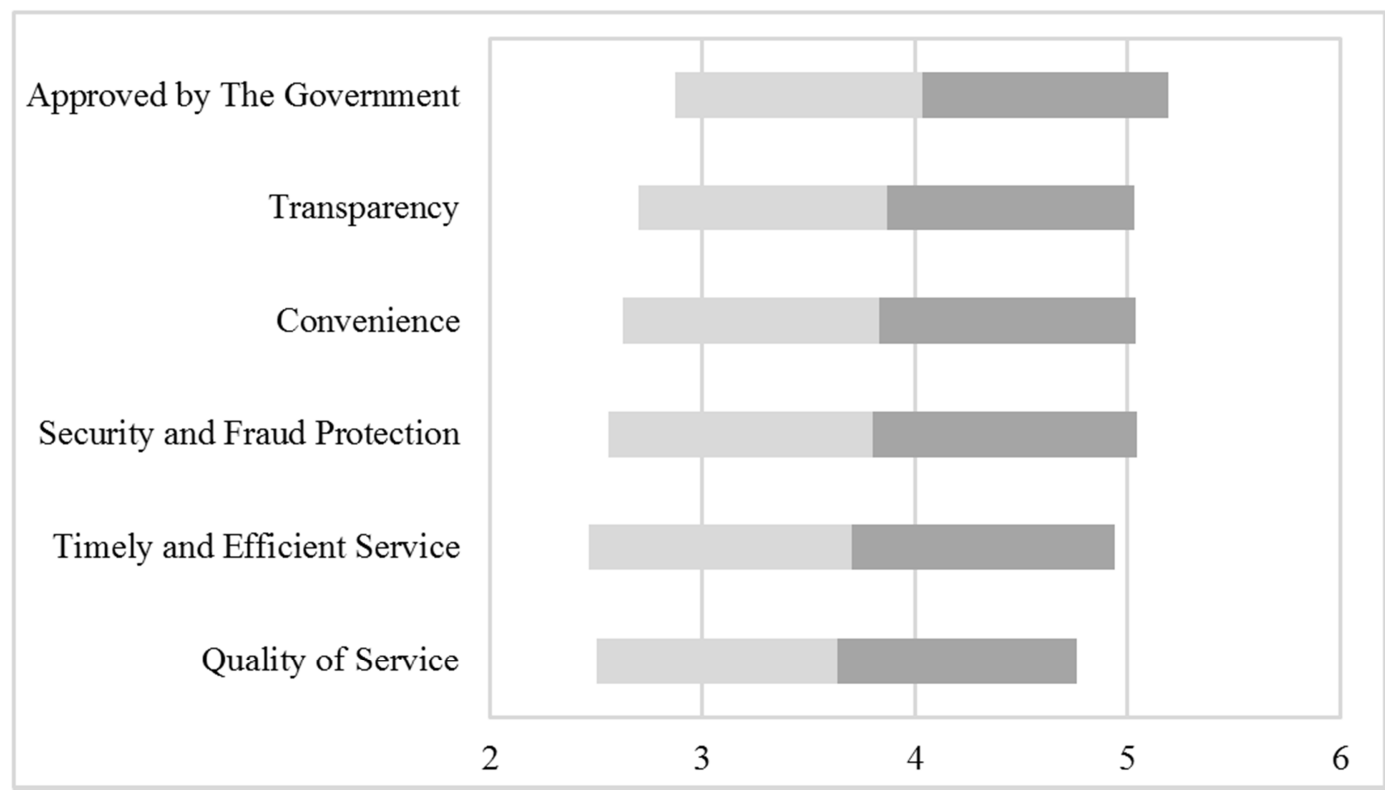

Figure 14. Respondents' Distribution in the Element of Consideration When Choosing Fintech. 


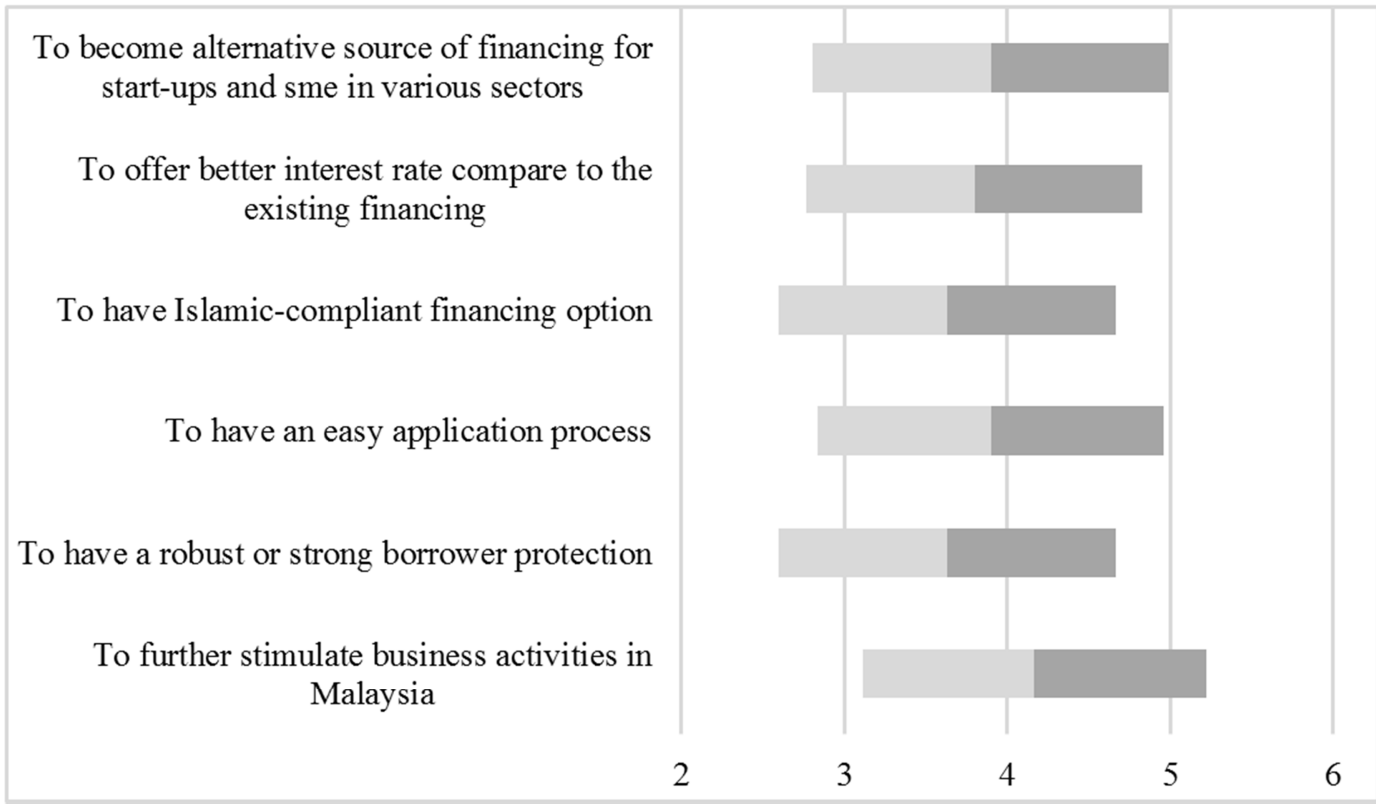

Figure 15. Respondents' Distribution in the Expectation of Fintech Development in Malaysia.

Apart from asking element of consideration when selecting FinTech as alternative financing, respondents were also asked their expectation and hope from FinTech development in Malaysia. List of expectations is collected from a preliminary study which was conducted in July 2017 and was ranked on a scale from 1, "Strongly Disagree" to 5, "Strongly Agree." Most of the respondents with a mean of 4.17 agree that development of FinTech would further stimulate business activities in Malaysia. Other than that, a majority of respondents also expect that application to apply for this new alternative instrument would be eased (with a mean 3.90) and hoping that it would become an alternative source of financing for SMEs and start-ups in various sectors (with a mean 3.90). Details of analysis results are shown in Figure 15 ( $\mu \pm \sigma$ chart $)$.

\section{Conclusion}

One year after the introduction of Fintech Regulatory Sandbox Framework in October 2016 by the Central Bank of Malaysia and approval of six P2P Financing Operators (November 2016) by Securities Commissions in Malaysia, the awareness and understanding of Malaysia SMEs and start-ups on the existence of FinTech (P2P lending and crowdfunding) were measured.

\subsection{Awareness}

In brief, based on answers from Q7 to Q9 and from Figure 11, we discovered that the level of awareness of most respondents is still very limited especially on P2P lending, crowdfunding as well as other FinTech services provided by non-bank financial institutions.

\subsection{Perception and Expectation}

However, based on the perception results, from Figure 12 and 13, a majority of respondents have a slightly positive response and perception to the development of FinTech. This result reflects a good sign regarding the acceptance of new financing options in Malaysia. Furthermore, the finding in Figure 14 suggests that new alternative financing channels with approval from the Malaysia Government and with proper regulations might accelerate the acceptance of alternative financing instruments in Malaysia. From Figure 14 and 15 , we found that a majority of the respondents are hoping that FinTech would be the best alternative financing option apart from traditional financing avenue, and FinTech development would further stimulate business activities in Malaysia soon.

\subsection{Recommendations}

The finding suggests that The Malaysian Government and related authorities need to put more effort not only in increasing the awareness and knowledge of SMEs and start-ups on alternative financing instruments but also how these alternatives can benefit them to move forward. One of the efforts which can be made is to further increase the financial literacy among Malaysian SMEs and start-up especially in FinTech as this financial knowledge would affect in increase firm total sources of financing. Besides, there were also evidences that show a positive relationship between the entrepreneurs' success and financial literacy.

At the grass-roots level, especially at the university level, Business Model Competition (BMC) based upon latest technology is proposed to be organized more often to increase awareness and interest of young people in FinTech and entrepreneurship. In terms of digital technology adoption among SMEs and start-ups, there is a need and proper initiatives to increase the level of technology adoption among SMEs and start-ups to a higher level and change the various aspects of business practices to encourage SMEs to move 
into the digital space.

Other than that, it is obvious that a level of confidence put by most SMEs and start-ups on the financial services provided by non-banks is still very low. Therefore, better promotion and guidance through mass and social media should frequently be implemented by authorized bodies to promote the potential of alternative financial option in helping and supporting SMEs and start-ups. On the government side, a more proper and coherent policy or regulations on alternative finance market should be imposed. In order to make sure that this market is providing proper financial services to the public, a strict regulatory enforcement should also be implemented.

Indeed, a continuous and effective inter- organizational collaboration among main players (Ministry of Finance, Central Bank of Malaysia and Securities Commission) in the government sector and Government-University-Industry (GUI) Partnership is crucial and essential in ensuring all those efforts successfully implemented and achieve the target.

\section{Survey Improvement}

These results might not be representing the whole awareness and perception of all SMEs and start-ups in Malaysia as the respondents' size in this survey is quite small compared to the actual numbers. Therefore, the author would like to suggest that a study with a more significant scale of respondents, and conducted by authorized government related body should be done in the future to get more consistent and accurate data.

\section{Acknowledgements}

I am grateful to the Malaysia-Japan Higher Education Program for providing financial support for this study.

\section{References}

[1] Arner, D. W., \& Janos B. (2015). FinTech in China: from the shadows? E\&Y Journal of Financial Perspectives: FinTech. [online] Available at: https://www.gfsi.ey.com/the-journal-of-financial-perspectives. php.

[2] Asaba, S., Aiba, K., Hirano, M. (2016). The Potential of the Fintech Industry to Support the Growth of SMEs in Indonesia, Raras Minerva Management Strategy and Industry Evolution, 35142338-8.

[3] Baeck, P., Collins, L., Zhang, B. (2014). Understanding Alternative Finance: The UK Alternative Finance Industry Report 2014.

[4] Ernst \& Young (2017). EY FinTech Adoption Index 2017: The rapid emergence of FinTech http://www.ey.com/Publication/vwLUAssets/ey-fintech-adopt ion-index-2017/\$FILE/ey-fintech-adoption-index-2017.pdf (Date Accessed: December 30, 2017).
[5] Fintech Regulatory Sandbox Framework (2016) http://www.bnm.gov.my/index.php?ch=en_announcement\&pg $=$ en announcement\&ac $=467 \&$ lang $=$ en (Date Accessed: December 30, 2017).

[6] Ignacio, D. L., \& Julian, M. (2017). The Role of Awareness in Crowdfunding Campaigns: The Empirical Evidence For The Caribbean. Inter-American Development Bank, Discussion Paper, IDB-DP-531.

[7] Information and Communications Technology (ICT) and Digital Adoption: E-Readiness of Malaysian SMEs (2017), http://acccimserc.com/file/file/2017\%20

Working\%20Papers/Final\%20Report\%20on\%20SMEs\%20Re adiness \%20in\%20Digital\%20Technology\%20-\%2019\%20Oct \%202017 (1).pdf (Date Accessed: December 30, 2017).

[8] Klaus Schwab, World Economic Forum (2017). The Global Competitiveness Report 2017-2018.

[9] Lucia, C. (2015). New Approaches to SME and Entrepreneurship Financing: Broadening the Range of Instruments, Economic Co-operation and Development (OECD), http://www.oecd.org/cfe/smes/New-Approaches-SME-full-rep ort.pdf (Date Accessed: September 30, 2017).

[10] Mollick, E. (2014). The Dynamics of Crowdfunding: An Exploratory Study, Journal of Business Venturing 29, 1- 16.

[11] Pierangelo, R. (2017). Siliconrepublic.com: Alternative finance: From Crowdfunding to P2P Lending, https://www.siliconrepublic.com/start-ups/alternative-financeic4-dcu-symposium (Date Accessed: September 30, 2017).

[12] Press Release, MasterCard (2013), Youth in Asia/Pacific's Developing Markets More Money Savvy, But Still Work to Be Done: MasterCard Index of Financial Literacy, https://newsroom. mastercard.com/press-releases/youth-in-asiapacifics-developin g-markets-more-money-savvy-but-still-work-to-be-done-mast ercard-index-of-financial-literacy/ (Date Accessed: September $30,2017)$.

[13] Rahman, M. P., \& Duasa, J. (2016). Factors Contributing To The Success of Crowdfunding: The Malaysian Case, Working Paper.

[14] Registered Market Operators in Malaysia (2016). https://www.sc.com.my/digital/list_rmo/(Date Accessed: December 30, 2017).

[15] Saksonova, S., \& Kuzmina-Merlino, I. (2017). Fintech as Financial Innovation - The Possibilities and Problems of Implementation, European Research Studies Journal, pp. 961-973.

[16] Shazida, J. M. K., Nur Syamilah. M. N., Abdul Rahim, A. (2016). Performance of Youth Entrepreneurs In Malaysia Micro Small and Medium Enterprises, International Journal of Economics and Financial Issues, 6 (S7) 86-91.

[17] Tran. K. C. (2006). Public Perception of Development Issues: Public Awareness Can Contribute to Sustainable Development of a Small Island. Ocean \& Coastal Management, 49, 367-383.

[18] Tubre, T. C., \& Collins, J. M. (2000). Jackson and Schuler (1985) revisited: A meta-analysis of the relationships between role ambiguity, role conflict, and job performance. Journal of Management, 26, 155-169. 
[19] World Bank; Enterprise Access to Finance (2014) http://pubdocs.worldbank.org/en/831911430846153177/MSM E-Finance-Survey-GEORGIA-EnterpriseAccessToFinance.pd f(Date Accessed: December 30, 2017).

[20] World Economic Forum Report (2015). The Future of FinTech: A Paradigm Shift in Small Business Finance.
[21] Yongwoon S., \& Dong-Hee, S. (2015). Analyzing China's Fintech Industry from the Perspective of Actor-Network Theory, Telecommunication Policy, Volume 40, Issues 2-3, March 2016, Pages 168-181. 